\title{
An Increase in Per Unit Cost: The Response from a Sales Maximizer and a Profit Maximizer
}

\author{
Lydia Gan*,a ${ }^{*}$ Shuntian $\mathrm{Yao}^{\mathrm{b}}$ and $\mathrm{Ke} \mathrm{Li}^{\mathrm{c}}$
}

\author{
${ }^{a}$ Department of Economics, Finance, and Decision Sciences, School of Business, University of North Carolina at \\ Pembroke, Pembroke, NC 28372, USA; ' Division of Economics, School of Humanities and Social Sciences, Nanyang \\ Technological University, Singapore; ' Graduate School of Business, Nihon University, Japan
}

\begin{abstract}
This paper investigates the decision making of firms with two different objectives - profit maximization and sales maximization, and compares their responses when encountering a higher per unit production cost or if per unit tax is imposed. The discussion in this paper is a follow up of $\mathrm{Li}$ and Yao [1], except in this case, a more comprehensive literature review is provided, and a very restricted result previously proposed has been substantially expanded to a few more general propositions.
\end{abstract}

Keywords: Profit maximization, per unit cost increase, sales maximization, JEL classification: D21, M21.

\section{INTRODUCTION}

In a recent paper by $\mathrm{Li}$ and Yao [1], the authors mainly focused on pointing out the theoretical flaws in Moschandreas [2, 3], in which the author proposed a proposition, arguing that when a per unit cost is incurred, the producer who maximizes sales always reduces the output more substantially than the producer who maximizes profits. In addition to pointing that Moschandreas' proposition is only valid for a very special case - when the cost functions are quadratic functions, a simple counter example was constructed by Li and Yao [1].

In this paper, we establish a much more general result than that shown in $\mathrm{Li}$ and Yao [1]. We intend to prove that, as long as the increase in per unit cost is not too substantial, a sales maximizer will show a more sensitive response than a profit maximize, no matter what cost function he has. As a result, a per unit tax introduced into a sales maximization industry may cause a much bigger negative welfare effect than if it were introduced into a profit maximization industry.

\section{LITERATURE REVIEW}

While Baumol [4] indicated that maximization of the growth rate of sales is a motivational assumption for an oligopolistic firm, Baldwin [5] found that profit maximization closely approximates the actual motive of the typical large firm. Yet others suggested that corporate recognition of public responsibility can be another managerial motivation.

Past studies suggested that the type of management control may affect the behavior of the firms. While Monsen

*Address correspondence to this author at the Department of Economics, Finance, and Decision Sciences, School of Business, University of North Carolina at Pembroke, Pembroke, NC 28372, USA; Tel: (910) 775-4265; Fax: (910) 521-6750; E-mail: lydia.gan@uncp.edu and Downs [6] observed that the interest of firms that are controlled by management does not necessarily coincide with owners' preferences, Boudreaux [7] and Palmer [8] proved that managers in management-controlled firms prefer activities that lead to lower risk than those resulting from owners' decisions in owner-controlled firms, given that both managers and owners are having the identical expected utility-maximization. Furthermore, Amihud and Kamin [9] found that revenue maximizing behavior is more prevalent among management-controlled firms than among ownercontrolled ones, and more prevalent among oligopolistic firms than among particularly competitive firms. Moreover, the market power of firms was found to have a greater influence on the firms' behavior than their type of control.

The constrained revenue maximization hypothesis has been explored in a variety of forms, among them are both single product and multi-product technologies with and without the embellishments[10-13]. One result is that given the resource base and cost structure/technology, both the sales maximizer and the profit maximizer will yield the same optimal output. Panik [14] showed that given resource, costs, and technology, both profit maximizers and profitconstrained sales maximizers may use different combination of inputs. Specifically, if both types of firms have the same maximal activity mix, then given the technology constraints, the shadow price for the input of the revenue maximizer will exceed that of the profit maximizer by its market price.

Zabojnik [15] analyzed the effects of providing managers with incentives to maximize sales in addition to profits on managerial efforts and human capital investment. According to Baker, Jensen, and Murphy [16], the salaries of top executives increased by $3 \%$ when the firm's sales increased by $10 \%$. Zabojnik's study revealed that the optimal incentive scheme for the manager in the presence of human capital investment will impact positively on sales and profits. For instance, by emphasizing sales, the worker's bargaining 
power will increase and hence he is more likely to acquire human capital that will eventually benefit the firm.

Applying the Cournot model for a duopolistic market in the automobile industry, Tabeta and Wang [17] provided an explanation for the huge trade deficit of the U.S. in relation to Japan based on an analysis of different strategic behaviors between U.S. firms and Japanese firms. There are several differences between Japanese and U.S. firms that result in the Japanese firm typically being more inclined to be a revenue maximizer, while the U.S. firm is more likely to be profit oriented. They showed that a revenue-maximizer (as in Japan) should obtain a larger market share and a higher profit than a profit-maximizer (like many in the U.S.). Blinder [18] too concluded that as long as it has a secure source of capital, a revenue-maximizer is at a distinct advantage when competing with profit-maximizers. Tabeta and Wang [17] further argued that if U.S. firms adopt a revenue maximizing strategy, an improvement in the trade deficit will result if they are in a matured market but mutual loss will be the consequence if they are in a declining market. In a declining market, the cultural-institutional equilibrium led to a bitter trade dispute; nevertheless, if both Japanese and U.S. firms adopted the profit maximizing strategy it would be an effective way of balancing trade.

\section{THE BACKGROUND}

In order to compare the decision-making of a profitmaximizing firm with a sales-maximizing firm, Baumol suggested three main differences between the behaviors of these two types of firms in his well-known book Economic Theory and Operation Analysis [19-21]. In the discussion, Baumol assumes that the sales maximizer is to choose an output to maximize the revenues while he is subject to some minimum profit constraint [21]. Baumol's theoretical results have been very influential, having been quoted by many management textbooks which are currently in use.

These results are later quoted by Moschandreas [2, 3] as three predictions:

Prediction 1. Compared with a profit maximzer, a sales maximizer produces more and charges a lower price for his product.

Prediction 2. A sales maximizer will tend to spend more on advertising and other sales promotional activities than a profit maximizer.

Prediction 3. A sales maximizer will increase price and reduce production in response to an increase in fixed costs or lump sum taxes.

As regards to Prediction 3, and according to Baumol, sale maximizers will react to an increase in fixed costs or lump sum taxes while profit maximizers will not simply because the profit maximizing criterion $\mathrm{MC}=\mathrm{MR}$ is not affected by an increase in fixed costs or lump sum taxes. However, Baumol did not provide any answer to the effect of an increase of per unit cost on the decision of a sales revenue maximizer nor that of a profit maximizer. In fact, answering this question is a bit more difficult than establishing the three predictions mentioned above. Moschandreas [2, 3] did try to establish a proposition as given below: ${ }^{1}$

Prediction 4. When an increase in variable costs or per unit tax is imposed, a sales maximizer will reduce output and increase price by a greater amount than a profit maximizer will.

Unfortunately this prediction is not correct in general. A counter-example was given by Li and Yao [1] who pointed out that this prediction is only valid for a very restricted case, i.e., when the cost functions are in quadratic form.

The contributions of $\mathrm{Li}$ and Yao [1] are somewhat limited in that there was no general conclusion as to under what circumstances the result of "Prediction 4" applies. In this paper we will conduct a deeper analysis in order to derive some general results particularly in theory and applications.

\section{SOME GENERAL RESULTS}

For simplicity, we only consider a monopoly firm or a firm in the perfect competition in our current model. We do not consider oligopolistic competition in this paper because the interaction among firms in such market makes the argument slightly more complicated. We leave it for future extension of this study.

We have seen that Prediction 4 in general is false. To compare the decision making of a profit maximizer and that of a sales maximizer in response to the increase of per unit cost, we need to make a more careful analysis. One important point we can make is that, whether the conclusion of Prediction 4 is true will depend on the minimum profit level $m$ the firm has to attain while maximizing the sales. We will establish a general result, and then concentrate on some special cases.

For simplicity we consider the case in which a firm has a continuous and strictly concave profit function $\pi=\pi(q)$ defined for all $q \in[0, \infty)$. Let $q^{*}$ be the unique maximum of $\pi(q)$ such that $\pi\left(q^{*}\right)>0$. It is reasonable to assume that for some $Q>q^{*}: \pi(Q)=0$ and $\pi(q)<0$ for $q>Q$. We will compare the individual response of a profit maximizer and a sales maximizer to the introduction of a per unit tax $t$.

After the introduction of per unit tax $t$, the new profit function is

$\bar{\pi}(q)=\pi(q)-t q$

$\bar{\pi}(q)$ is obviously continuous and strictly concave. As a result, $\bar{\pi}(q)$ has a unique maximum $\bar{q}$, and of course $\bar{\pi}(\bar{q})<\pi\left(q^{*}\right)$.

Let $m>0$ be the minimum profit requirement for a sales maximizer. It is reasonable to assume that $m \leq \bar{\pi}(\bar{q})$, otherwise the sales maximizer can never fulfill the minimum profit requirement.

\footnotetext{
${ }^{1}$ Please refer to Moschandreas [2], pp. 279-280; and Moschandreas [3], pp. 202203
} 
According to our assumptions, $\pi=\pi(q)$ must be strictly decreasing in the interval $\left[q^{*}, \infty\right]$, and there exists a unique $Q^{*}$ in this interval such that $\pi\left(Q^{*}\right)=m$, Note that $q^{*}$ and $Q^{*}$ will be the respective output of a profit maximizer and a sales maximizer before per unit tax is introduced. And note that the value of $Q^{*}$ depends on $m$, and since $\pi(q)$ is strictly increasing and continuous in $\left[q^{*}, \infty\right], Q^{*}=Q^{*}(m)$ is well-defined and is continuous in $m$.

After per unit tax is introduced, as mentioned above, a profit maximizer will produce quantity $\bar{q}$. Note that $\bar{\pi}(q)$ is strictly decreasing and eventually becomes negative. There must exist a unique $\bar{Q}>\bar{q}$ such that $\bar{\pi}(\bar{Q})=\pi(\bar{Q})-t \bar{Q}$-. $=m$ This $\bar{Q}$ is the quantity produced by the sales maximizer after per unit tax is introduced. Again $\bar{Q}$ depends on $m$, and $\bar{Q}=\bar{Q}(m)$ is well-defined and continuous. To compare the values of $q^{*}, \bar{q}, Q^{*}, \bar{Q}$, we have:

Lemma. We always have $\bar{q}<q^{*}$ and $\bar{Q}(m)<Q^{*}(m)$ for every $m$, i.e. when the per unit cost increases or the per unit tax is introduced, both the profit maximizer and the sales maximizer will reduce their outputs.

Proof. Because the profit function $\pi=\pi(q)$ is strictly concave, the derivative $\pi^{\prime}(q)$ is decreasing. Note that $q^{*}$ is determined by $\pi^{\prime}\left(q^{*}\right)=0$ and $\bar{q}$ is determined by $\bar{\pi}^{\prime}(\bar{q})=\pi^{\prime}(\bar{q})-t=0$ or $\pi^{\prime}(\bar{q})=t$. Thus, $\pi^{\prime}(\bar{q})>\pi^{\prime}\left(q^{*}\right)$ implies $\bar{q}<q^{*}$.

To see that $\bar{Q}(m)<Q^{*}(m)$, we consider two cases. If $\bar{Q}(m) \leq q^{*}$, then $\bar{Q}(m)<Q^{*}$ is trivial. If $\bar{Q}(m)>q^{*}$, then $\pi(\bar{Q}(m))=m+c \bar{Q}(m)>m=\pi\left(Q^{*}\right)$ and that $\pi(q)$ is decreasing in $\left[q^{*}, \infty\right]$ and this implies $\bar{Q}(m)<Q^{*}$. QED.

We will establish a general result:

Proposition 1. Assume that the profit function $\pi(q)$ is continuous and strictly concave. When per unit tax $t$ is introduced and the profit maximizer reduces her output from q* to $\bar{q}$, there always exists an interval $(\underline{m}, \bar{\pi}(\bar{q})]$, such

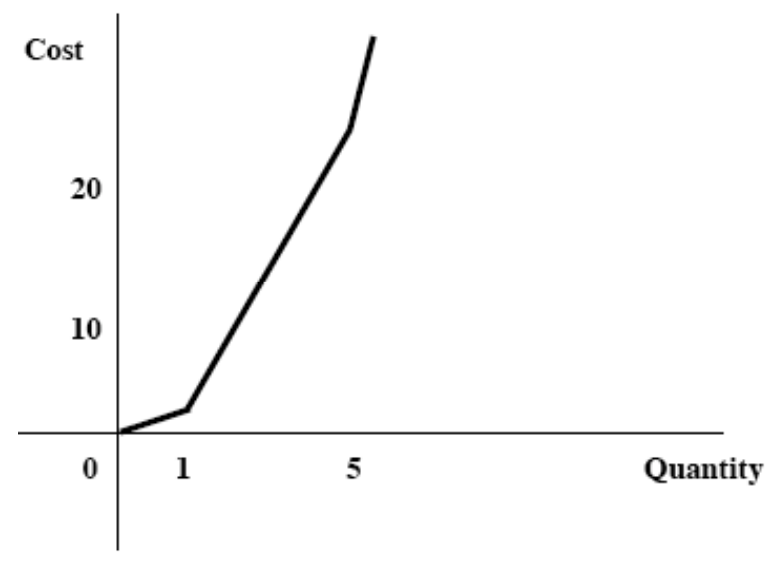

Fig. (1). Cost function. that when $m \in(m, \bar{\pi}(\bar{q})]$, the sales maximizer will reduce output and increase price by an amount greater than $\left(\mathrm{q}^{*}-\bar{q}\right)$.

Put in another way, proposition 1 states: If the minimum profit requirement upon a sales maximizer is sufficiently high, then his reaction to the introduction of per unit tax will be more substantial than that of a profit maximizer.

Proof. What we want to show is that in some interval of $m$ :

$Q^{*}(m)-\bar{Q}(m)>q^{*}-\bar{q}$

For $\quad m=\bar{m}=\bar{\pi}(\bar{q}) \quad$ we have: $\quad \bar{Q}\left(m^{*}\right)=\bar{q}, Q,-$ $*\left(m^{*}\right)>q *$ and therefore

$Q^{*}(\bar{m})-\bar{Q}(\bar{m})>q^{*}-\bar{q}$

Note that $Q^{*}(m)-\bar{Q}(m)$ depends on $m$ continuously. Thus there exists a neighborhood of $\bar{m}$ in which proposition 1 remains true. In particular, there is an interval $(\underline{m}, \bar{m}]=(\underline{m}, \bar{\pi}(\bar{q})]$ in which proposition 1 holds. QED.

Example 1. Assume the inverse demand function for the firm being

$p=5-0.01 q$.

where $q$ is the quantity produced by the firm and $p$ is the market clearing price. Assume that this firm has the piecewise linear cost function originally, as shown in Fig. (1).

$\mathrm{TC}= \begin{cases}q ; & q \in[0,1) \\ 4.75 q-3.75 ; & q \in[1,5) \\ 7.5 q-17.5 ; & q \in[5, \infty)\end{cases}$

This was the counter-example in which Li and Yao [1] showed that Moschandreas's "Prediction 4" is in general not correct. They assumed that the minimum profit required for the firm was $m=2$, comparing the decision changes between a profit maximizer and a sales maximizer when per unit cost was increased by 0.5 . They showed that the profit maximizer reduced his output by 4 , and yet the sales maximizer reduced her output by 0.97 only.

However, for this same example, with per unit cost increased by the same amount of 0.5 , if we confine the minimum profit values of $m \in(3.341,3.49)$ other than maintaining $m=2$, then the result in Moschandreas's "Prediction 4" would have been correct. (see Fig. 2). Therefore, in general which type of producer adjusts more in terms of output will depend on the magnitude of the minimum profit he or she wants to guarantee.

By the way, for some special forms of profit functions, the conclusion of Proposition 1 is true for all values of $m$, i.e. for all $m \in(-\infty, \bar{m}]$. All quadratic profit functions are in this category.

Proposition 2. Assume that the firm has a linear inverse demand function $p=A-B q$ and a quadratic cost function $T C=C+D q+E q^{2}(A>0, B>0, D>0, C \geq 0, E \geq 0$ are all constants), then when per unit cost increases or per unit tax 


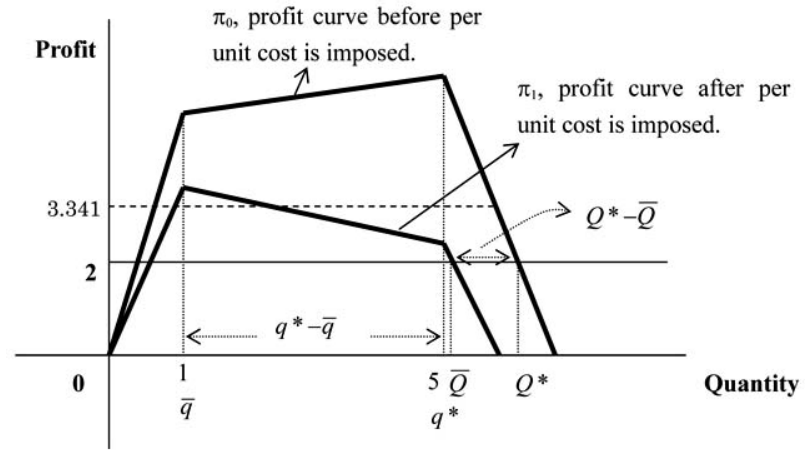

Fig. (2). The decision makings of a profit maximizer and a sales maximizer before and after the imposition of per unit cost (example 1).

Notes: When profit $=2$, note that $q^{*}-\bar{q}>Q^{*}-\bar{Q}$, where

$q^{*}=$ Output produced by a profit maximizer before the imposition of a per unit cost

$\bar{q}=$ Output produced by a profit maximizer after the imposition of a per unit cost

$Q^{*}=$ Output produced by a sales maximizer before the imposition of a per unit cost $\bar{Q}=$ Output produced by a sales maximizer after the imposition of a per unit cost

is imposed, a sales maximizer will reduce output and increase price by a greater amount than a profit maximizer.

Proof. It is easy to derive the profit function

$\pi=-C+(A-D) q-(B+E) q^{2}$

For convenience we introduce the notations:

$C=\gamma, A-D=\beta, B+E=\alpha$

Then we can write

$\pi=-\alpha q^{2}+\beta q-\gamma$

It is reasonable to assume that $\beta>0$ and $\beta^{2}>4 \alpha \gamma$ so that there exists a range of $q$ for positive profits. It is easy to compute the optimal quantity for profit maximization:

$$
q^{*}=\frac{\beta}{2 \alpha}
$$

Imagine that per unit cost increases by $t$, so the profit function is changed to $\bar{\pi}(q)=-\alpha q^{2}+(\beta-t) q-\gamma$. Again it is reasonable to assume that $t<\beta$ so that the maximum profit is positive. It is easy to verify that the optimal quantity for profit maximization is:

$$
\bar{q}=\frac{\beta-t}{2 \alpha}
$$

and the maximum profit is:

$$
\bar{m}=\bar{\pi}(\bar{q})=\frac{(\beta-t)^{2}}{4 \alpha}-\gamma
$$

Thus we have $q^{*}-\bar{q}=\frac{t}{2 \alpha}$. We need to verify for all $m \leq \bar{m}:$

$Q^{*}(m)-\bar{Q}(m)>\frac{t}{2 \alpha}$

Note that $Q^{*}(m)$ and $\bar{Q}(m)$ are, respectively, the larger root of the equations:

$-\alpha q^{2}+\beta q-\gamma=m$, and $-\alpha q^{2}+(\beta-t) q-\gamma=m$

By directly solving quadratic equations:

$Q^{*}(m)=\frac{\beta+\sqrt{\beta^{2}-4 \alpha(\gamma+m)}}{2 \alpha}$, and
$\bar{Q}(m)=\frac{\beta-t+\sqrt{(\beta-t)^{2}-4 \alpha(\gamma+m)}}{2 \alpha}$

We thus have:

$Q^{*}(m)-\bar{Q}(m)=\frac{t}{2 \alpha}+\frac{\sqrt{\beta^{2}-4 \alpha(\gamma+m)}-\sqrt{(\beta-t)^{2}-4 \alpha(\gamma+m)}}{2 \alpha}>\frac{t}{2 \alpha}$

The inequality holds because

$\sqrt{\beta^{2}-4 \alpha(\gamma+m)}-\sqrt{(\beta-t)^{2}-4 \alpha(\gamma+m)}>0$

QED.

For a general "negative" result we have:

Proposition 3. Define $\mathrm{d}=\mathrm{q}^{*}-\bar{q}$. If for the minimum profit level $\mathrm{m}$, it holds that $\bar{\pi}(\bar{Q}(m))>\pi(\bar{Q}(m)+d)$, then a sales maximizer reduces output and increases price by a smaller amount than the profit maximizer.

Proof. By definition $\bar{\pi}(\bar{Q}(m))=\pi\left(Q^{*}(m)\right)$. Therefore $\bar{\pi}(\bar{Q}(m))>\pi(\bar{Q}(m)+d)$ implies $\pi\left(Q^{*}(m)\right)>\pi(\bar{Q}(m)+d)$. Because $\pi(q)$ is strictly decreasing in $\left[q^{*}, \infty\right]$, we thus have $Q^{*}(m)<\bar{Q}(m)+d$, which is equivalent to $Q^{*}(m)-\bar{Q}(m)<q^{*}-\bar{q}$. QED.

Let us give an example to illustrate the result of Proposition 3. This seems to be a more "natural" counterexample against Moschandreas' result.

Example 2. Consider a firm with profit function $\pi(q)=-(q-5)^{4}+5$ (say, with inverse demand $p=500-q$, and $\left.\mathrm{TC}=q^{4}-20 q^{3}+150 q^{2}+620\right)$. The optimal output for profit maximization is $q^{*}=5$. Imagine that the government imposes a per unit tax of 0.5 . Then the new profit function is $\bar{\pi}(q)=-(q-5)^{4}-0.5 q+5$, and the new optimal output for profit maximization is 4.5 , i.e. $d=$ 0.5 . Now consider the decision of a sales maximizer. Assume that the minimum profit required is $m=1$. It is easy to compute $\bar{Q}=6$.

By direct calculation,

$$
\pi(\bar{Q}+d)-\bar{\pi}(\bar{Q})=\pi(6.5)-\bar{\pi}(6)=-0.0625-1<0
$$


Thus by Proposition 3, the sales maximizer reduces output and increases price by a smaller amount than the profit maximizer. In fact, before per unit tax is imposed, the sales maximization output is $6.36778 \ldots$; after the tax is imposed, the sales maximization output is $5.99035 \ldots$. The change in output is 0.37 .

\section{WHAT'S THE WRONG WITH THE ARGUMENT FOR PREDICTION 4?}

Moschandreas' [2, 3] argument for Prediction 4 was made by applying the idea of geometric transformation. It is argued that, after per unit tax is introduced, the total cost curve is shifted upward and pivoted to the left - or more precisely - rotated counter-clockwise. (And as a result, the profit curve is shifted downward and rotated clockwise.) This is generally incorrect. In most cases, the new cost curve cannot be obtained from the old one through a translation and a rotation, and neither can the new profit curve be obtained from the old one through a translation and a rotation. To see this, it is sufficient to show that the new curve is not congruent with the old one, because the transformation from the old to the new is not distancereserved.

Let us revisit Example 1. The new cost curve $C_{1}$ and the old one $\mathrm{C}_{0}$ are sketched in Fig. (3).

The two corner points on the old cost curve $\mathrm{C}_{0}$ are $(1,1)$ and $(5,20)$, and the two corner points on the new cost curve $\mathrm{C}_{1}$ are $(1,1.5)$ and $(5,22.5)$. Obviously the distance between the two corner points on the new cost curve is greater than that between the two corner points on the old cost curve.

Let us revisit Example 2. The profit curve $\pi_{3}$ before per unit tax introduced and $\pi_{4}$, the profit curve after per unit tax is introduced are shown in Fig. (4). Obviously $\pi_{4}$ cannot be obtained from $\pi_{3}$ through a translation and a pivot to the right.

\section{CONCLUSION}

Having discussed completely the responses of a profit maximizer and a sales maximizer to the introduction of per

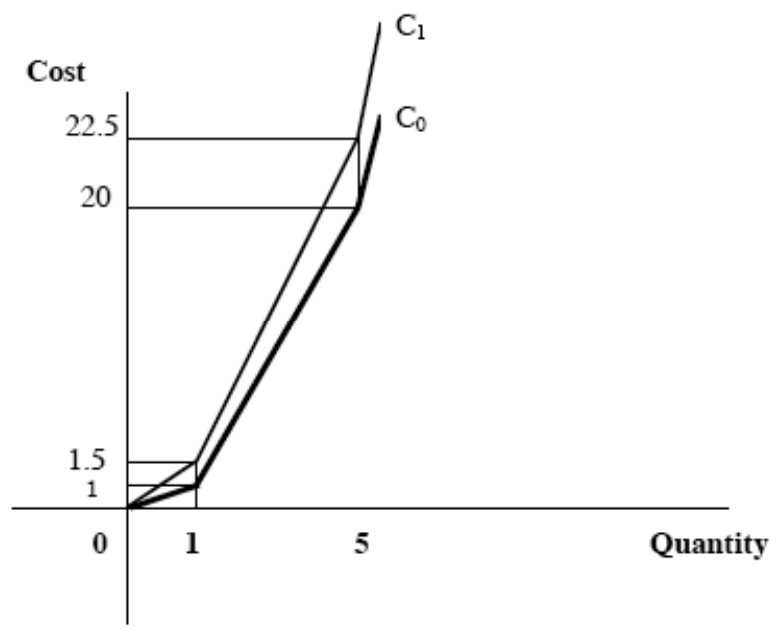

Fig. (3). Cost functions before and after the imposition of per unit tax.

unit tax (or per unit cost increase), we establish general results as stated in Proposition 1 and Proposition 2. In addition, we point out that in other cases, Prediction 4 by Moschandreas [2, 3] can be false. As long as the increase in per unit cost is not too substantial, a sales maximizer will show a more sensitive response than a profit maximize, no matter what cost function he has. Since a per unit tax introduced into a sales maximization industry may cause a much bigger negative welfare effect than if it were introduced into a profit maximization industry, when the government considers an introduction of per unit sales tax into an industry, it pays to estimate the welfare effects accordingly, and on a case-by-case basis.

The goal of sales maximization can be explained by the management's desire to maintain a firm's competitive position, which depends largely on its size. Unlike the shareholders who are interested in profit, the management is interested in sales revenue, either because large sales revenue is a matter of prestige or because its remuneration is often related to the size of the firm's operations than to its profits.

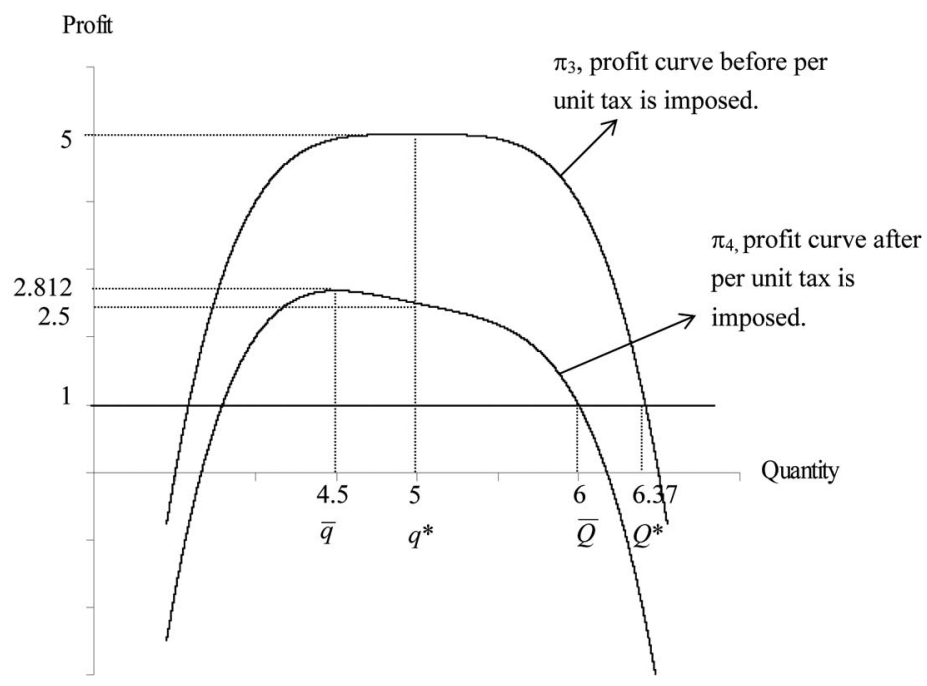

Fig. (4). The decision makings of a profit maximizer and a sales maximizer before and after the imposition of per unit tax (example 2). 
In practice sales maximization is quite frequently observed in many industries. As mentioned earlier, in the case of the automobile industry, it has been shown that the adoption of a revenue maximizing strategy by U.S. firms can lead to an improved trade deficit in a matured market but it can result in mutual loss in a declining market [17]. And an effective way of balancing the trade would be for both Japanese and U.S. firms to adopt the profit maximizing strategy. Additionally, Blinder [18] demonstrated that a revenuemaximizer with a strong financial backing has more competitive advantages than his profit-maximizing partner. Furthermore, in the market for human capital, Zabojnik [15] found that it may be optimal for owners of firms who maximize profits to provide managers with incentives to maximize sales in addition to profits. This may affect the result of the bargaining game between workers and managers on workers' wages, and it may also solve the problem of underinvestment by workers in specific human capital. It can be demonstrated further that an optimal managerial contract is a function of sales in addition to profits. In summary, these studies highlight the importance of the behavior of a salesmaximizer and the application of sales maximization in management sciences.

\section{REFERENCES}

[1] Li K, Yao S. Sales maximization and profit maximization, a note on the decision of a sales maximizer to the increase of per unit cost. Pacific Eco Rev 2007; 12(5): 559-64.

[2] Moschandreas M. Business economics. New York: Routledge 1994.

[3] Moschandreas M. Business economics $2^{\text {nd }}$ ed. Thomson Learning 2000.

[4] Baumol WJ. Business behavior, value and growth. New York: Macmillan 1959.
[5] Baldwin WL. The motives of managers, environmental restraints, and the theory of managerial enterprise. Quarterly J Eco 1964; 78(2): 238-56.

[6] Monsen RJ, Downs A. A theory of large managerial firm. J Politic Eco 1965; 73(3): 221-36.

[7] Boudreaux KJ. Managerialism and risk-return performance. Southern Eco J 1973; 39(3): 366-72.

[8] Palmer J. The profit-performance effects of the separation of ownership from control in large U.S. industrial corporations. Bell J Eco Manage Sci 1973; 4(1): 293-303.

[9] Amihud Y, Kamin J. Revenue vs. profit maximization: differences in behavior by the type of control and by market power. Southern Eco J 1979; 45(3): 838-46.

[10] Sandmeyer RL. Baumol's sales maximization model: comment. Am Eco Rev 1964; 54(6): 1073-80.

[11] Haveman R, DeBartolo G. The revenue maximization oligopoly model: comment. Am Eco Rev 1968; 58(5): 1355-58.

[12] Hawkins CJ. The revenue maximization oligopoly model: comment. Am Eco Rev 1970; 60(3); 429-32.

[13] Kafoglis M, Bushnell R. The revenue maximization oligopoly model: comment. Am Eco Rev 1970; 60(3); 427-28.

[14] Panik MJ. Constrained sales maximization under a linear technology. Int Rev Eco Finance 1993; 2(4); 417-24.

[15] Zabojnik J. Sales maximization and specific human capital. RAND J Eco 1998; 29(4): 790-802.

[16] Baker GP, Jensen MC, Murphy KJ. Compensation and incentives: practice $v s$. theory. J Finance 1988; 43(3): 593-616.

[17] Tabeta N, Wang R. Who will be the winner when a profitmaximizer meets a revenue-maximizer? The case of US-Japan auto trade. 1996. Available from: http://www.ntu.edu.sg/nbs/sabre/working_papers/19-96.pdf [Accessed in December 2006].

[18] Blinder AS. A simple note on the Japanese firm. J Jpn Int Econom 1993; 7(3): 238-55.

[19] Baumol WJ. Monopolistic competition and welfare economics. Am Eco Rev 1964; 54(3): 44-52.

[20] Baumol WJ. Business behavior, value and growth revised ed. New York: Harcourt Brace and World, Inc 1967.

[21] Baumol WJ. Economic theory and operations analysis $4^{\text {th }}$ ed. New Jersey: Prentice Hall 1977.

Received: March 29, 2009

Revised: May 06, 2009

Accepted: May 25, 2009

(C) Gan et al.; Licensee Bentham Open.

This is an open access article licensed under the terms of the Creative Commons Attribution Non-Commercial License (http://creativecommons.org/licenses/by-nc/3.0/) which permits unrestricted, non-commercial use, distribution and reproduction in any medium, provided the work is properly cited. 